\title{
“O que aconteceu com o Sr. Mutt?"
}

\author{
Eliane Maass $^{1}$
}

\section{Introdução}

\begin{abstract}
"Os grandes deuses brancos, as coisas que mantêm nossa economia em andamento geladeiras, fogões, tudo que antes era de porcelana e branco -, agora são pintados. Isso é novo. Vem com a pop art. Muito bacana. $O$ mágico Mandrake saindo da parede para a gente quando se abre a geladeira para pegar o suco de laranja."
\end{abstract}

Para o autor destas palavras, "a tecnologia transformou o mundo das artes, embora mais cedo e mais completamente o das artes e diversões populares que o das 'grandes artes', sobretudo as mais tradicionais" ${ }^{\prime 3}$. A década de 1950 é o triunfo do rock'n roll, do blues urbano dos guetos negros norteamericanos, de símbolos reconhecidos e amados pelos massas. A arte se tornava mais popular, voltada aos interesses e gostos do povo, ao mesmo tempo em que se construíam e destruíam símbolos e mitos de consumo. Mas o maior "mito" ainda era o sentimento de superioridade americana, a exacerbação do nacionalismo de uma sociedade que, vista de perto, vivia um sentimento de frustração e vazio. Este vazio interior buscava-se preencher com a concretização do exterior, ou seja, a partir de uma valorização dos objetos de consumo. As campanhas de publicidade visavam vender "não o bife, mas o chiado", não o sabonete, mas o sonho de beleza, não as latas de sopa, mas a felicidade familiar.

No século XVIII, com a Revolução Francesa, a arte tornou-se oficial e nacional nas mãos de artistas como David e, posteriormente, Delacroix no Romantismo. Marat e A Liberdade guiando o povo foram os símbolos iconográficos de uma "era das revoluções". O final do século XIX e início do $\mathrm{XX}$ foi marcado por vários conflitos e duas guerras mundiais que enfraqueceram grande parte do mundo. Durante esse turbulento período da Primeira Guerra Mundial, um grupo de artistas mobilizou-se na Europa e na

\footnotetext{
${ }^{1}$ Graduação - História/UFPR (PET-SESu).

${ }^{2}$ Studs Terkel, Division street: America (1967, p.217) In: HOBSBAWM, Eric. Era dos Extremos: o breve século XX, 1914-1991. São Paulo: Cia das Letras, 1997. P.483.

${ }^{3}$ HOBSBAWM, Eric. Op.cit. P.485.
} 
América com um mesmo objetivo de lutar contra os "delírios mortais de seu tempo"4 através da produção de uma "arte da destruição". "A revolta dos dadaístas envolveu um tipo complexo de ironia, porque eles próprios eram dependentes da sociedade condenada, e a destruição desta e de sua arte significaria, pois, a destruição deles próprios como artistas. Assim, num certo sentido, o dadá existiu para se destruir." Contudo, se de um lado o dadá se destruiu, de outro, lançou os fundamentos para um "novo dadá", anunciado no neo-realismo, na pop art, na minimal, e arrisco acrescentar, na arte contemporânea.

Desprovido de sentido, como dizia Arp, o dadaísmo é uma arte do acaso e deliberada, que se preocupa, fundamentalmente, com a nãosuperioridade do artista como criador. Nesse sentido, Duchamp foi irônico assinando sua obra Fonte com o nome $R$. Mutt, uma firma que produzia artigos sanitários $^{6}$. Para ele, todas as pinturas do mundo são ready-mades, já que os tubos de tintas usados pelos artistas são produtos manufaturados e ready-mades e, portanto, não é possível começar do nada, pois se começa pelos readymades, os quais podem ser os próprios pais do artista ${ }^{7}$. Conhecendo as declarações de Duchamp, artistas da década de 50 e 60 ainda insistiam em "fazer algo do nada", o que é explicado pelo fato de em todo tempo buscar-se romper normas e impedir uma arte "acomodada".

Andy Warhol, assim como outros artistas modernos e contemporâneos, foi influenciado pelas idéias de Duchamp, e motivado pelo mesmo sentimento de crítica a sociedade e a arte. Contudo, enquanto Duchamp fugia do juízo estético dado aos objetos - como era a filosofia da Bauhaus -, Warhol e os demais artistas pop retomaram a beleza estética dos objetos. Numa carta de Marcel Duchamp à Hans Richter, aquele declara: "Esse neo-dadá, a que eles chamam neo-realismo, arte pop, Assemblage, etc., é uma saída fácil e sustentase do que o Dadá fez. Quando descobri os ready-mades pensei estar desencorajando a estética. No neo-dadá, eles tomaram os meus ready-mades e recuperaram a beleza estética neles. Joguei-lhes o porta-garrafas e o mictório na cara como um desafio... e agora eles os admiram por sua beleza estética!",

Entre semelhanças e diferenças a pop art foi se formando a partir do movimento dadá, e os artistas da década de 1950/60 representaram sua arte dentro ou próximo de preceitos colocados nas três décadas anteriores. Nesse

\footnotetext{
${ }^{4}$ ADES, Dawm. Dadá e Surrealismo In: STANGOS, Nikos (org.) Conceitos da Arte Moderna. Rio de Janeiro: Editora Zahar, 1995. P.82.

${ }_{5}^{5}$ ADES, Dawm. Op.cit. P.82.

${ }^{6}$ RICHTER, Hans. Dadá: arte e antiarte. São Paulo: Martins Fontes, 1993. P.116.

${ }^{7}$ VENÂNCIO FILHO, Paulo. Marcel Duchamp. P.23.

${ }^{8}$ LUCIE-SMITH, Edward. Arte Pop. In: STANGOS, Nikos (org.) Conceitos da Arte Moderna. Rio de Janeiro: Editora Zahar, 1995. P.161.
} 
sentido, pretendo apresentar a pop art como fruto do dadá nos Estados Unidos, e o trabalho de Andy Warhol como inspiração em Duchamp.

\section{"Vamos introduzir um pouco de inteligência na pintura..."}

Quando Duchamp proferiu tais palavras estava no início de uma carreira de artista e filósofo da arte, e já entendia que era necessário realizar mais do que um trabalho estético e comercial, mas dar lógica à arte. "O readymade era a dedução lógica a que Duchamp havia chegado a partir da recusa dos empreendimentos comerciais com a arte, e da incerteza quanto a um sentido da vida, de modo geral"". Ele considerava função da arte uma reflexão, um procedimento conceitual, quase uma ética. Dessa forma, a arte é o modo como a olhamos, conforme o título que lhe atribuímos.

Como o dadá era a favor do não sentido, o que não significa contrasenso, seus artistas realizaram várias obras ligadas ao acaso, apresentando também objetos transitórios, desprovidos de significado, com uma intenção provocativa. Duchamp gostava de denominar sua posição de antiarte como "aarte", o que equivale a a-moral, ou seja, um esvaziamento não apenas da arte, mas também uma redução dos conteúdos da alma na vida ${ }^{10}$. Os próprios readymades são obras a-arte, resultantes de experiências intelectuais, e não sensoriais, compreendidas no caminho a que conduzem. Segundo Duchamp, "antes, a pintura era sempre um meio para um fim, fosse ele religioso, político, social, decorativo ou romântico. Hoje é um fim em si""11.

Marcel queria chocar o público ao expor o $N u$ no Salão dos Independentes, e ao tentar expor o urino. Este não foi aceito na $1^{\mathrm{a}}$ Exposição dos Indépendants em Nova Iorque, mas tornou-se a principal peça de numerosas exposições nos anos cinqüenta. Mesma época em que despontavam Andy Warhol, Lichtenstein, e outros artistas pop.

A respeito da rejeição do urinol no Indépendants, Duchamp declara:

"O fato de saber se Mutt faz a fonte com as próprias mãos, ou não, não tem a menor importância. Escolheu-a. Pegou um objeto qualquer do mundo doméstico e situou-o de forma a fazer desaparecer o objeto utilitário atrás de um novo nome e de um ponto de vista novo, inventando, pois, um novo sentido para esse objeto. É absurdo falar-se da arte de trabalhar o chumbo. As únicas obras de arte que a América produziu são utensílios sanitários e potes."

A partir dessa declaração entende-se o dadaísmo como precursor da pop art. Os ready-mades como obras de arte enquanto objeto, onde o cotidiano

\footnotetext{
${ }^{9}$ RICHTER, Hans. Op. cit. P.117.

${ }^{10}$ RICHTER, Hans. Op. cit. P.119.

"VENÂNCIO FILHO, Paulo, Op. cit. P.16. 
se torna arte e a arte se torna o cotidiano. O dadaísmo associava textos publicitários, imagens, slogans, panfletos revolucionários, elementos do quotidiano e da arte popular para deles fazer colagens, quadros gráficos, fotografias, filmes, assemblages, teatro, representações. Essas combinações inesperadas, em parte surrealistas, integrando tudo, tanto os princípios de organização racional como componentes aleatórios, influenciaram a pop art e o happening do fim dos anos cinqüenta ${ }^{12}$.

\section{"Esta é a verdadeira arte da propaganda, que faz propaganda para si própria, como uma arte que detesta a propaganda"}

(Harold Rosenberg, no New Yorker) ${ }^{13}$

A pop art é um fenômeno artístico que expressa o espírito de uma época, na caso, a década de 1960, de uma sociedade industrial, capitalista e tecnológica. "A palavra pop torna-se o slogan sorridente de uma ironia crítica relativamente às palavras divulgadas pelos meios de comunicação cujas histórias fazem a História, cuja estética define a imagem de uma época e os exemplos estereótipos influenciam o comportamento dos homens" "14. É uma arte das grandes metrópoles, como Nova Iorque e Londres. Naquela, segundo Robert Henri, "a questão da nacionalidade na arte é insolúvel, sem dúvida... a arte de uma nação está no seu apogeu quando mostra o caráter de um povo da forma mais fiel",

A sociedade norte-americana pós-guerra é marcada pela trivialidade (kitsch) - comunicação entre produtor e consumidor -; pelo questionamento da arte elitista; pelo movimento dos hippies - num desejo de abolição da tutela moral e das hierarquias sociais -; por ídolos de emancipação como Elvis Presley e James Dean (clichês de Hollywood); por uma indústria do entertainment, vinculados a música pop (Beatles, Rolling Stones); e por um questionamento dos modos de apresentação, organização e coleção admitidos em museologia.

As explicações para as experiências sociocríticas do mito americano encontram-se em diversos fatores. As fotografias dos Estados Unidos nos anos 20 e 30 , descrevendo o cotidiano urbano e rural, aspectos da industrialização, e sua transformação pelos meios de comunicação, inspiram o "pensamento pop". Após a época de crise econômica e política, ocorre o progresso de uma cultura

\footnotetext{
${ }^{12}$ OSTERWOLD, Tilman. Pop Art. Taschen, 1994. P.132.

${ }^{13}$ RICHTER, Hans. Op. cit. P.285.

${ }^{14}$ OSTERWOLD, Tilman. Op. cit. P.6.

${ }^{15}$ OSTERWOLD, Tilman. Op. cit. P.134. 
de massas, da tecnologia e da industrialização dos prazeres. No campo teórico, Walter Benjamin e Siegfried Kracauer propõe "uma transformação dos hábitos visuais e dos comportamentos nos domínios da produção e recepção da arte em relação à extensão progressiva da oferta" "16 , desembocando na era pop. Marshall McLuhan aborda em sua tese a manipulação do homem pelos "media"17, o nascimento de uma cultura para as massas, e uma arte crítica objetivando a reprodutibilidade.

Walter Benjamin observou que "a era da 'reprodutibilidade técnica' transformou não apenas a maneira como se dava a criação - assim tornando o cinema e tudo que dele derivava (televisão, vídeo) a arte central do século mas também a maneira como os seres humanos percebiam a realidade $\mathrm{e}$ sentiam as obras de criação" "18. A arte tornou-se mais cooperativa que individual, mais tecnológica que manual. Para Benjamin, numa reprodução há uma busca da autenticidade sem sentido, pois seu valor de culto foi substituído pela autenticidade, e não há mais uma função ritualista. "Multiplicando as cópias, elas transformam o evento produzido apenas uma vez num fenômeno de massas"19. Walter atribui às mudanças sócio-históricas o declínio da aura ligada aos objetos históricos -, e a vulgarização da arte como causa das técnicas de reprodução.

Andy Warhol nega a história, apresentando tudo como absolutamente passado, deteriorado, onde a pura imagem do valor estético está no passado, porque no presente é "antiestética", já que está presa à lei de consumo. O juízo determina o valor, que está no consumo, mas numa sociedade de massa, onde todos são testemunhas, ninguém é juiz: “o que 'faz notícia' não faz história”. E acrescenta, "quem 'faz' o valor estético, em suma, não é o artista, mas o consumidor normal de produtos industriais".,"20

A sociedade de uma cultura consumista, de meios de comunicação e euforia tecnológica, pôs em prática os "mitos do cotidiano". De forma antagônica expôs o progresso e desagregação num espírito de vulnerabilidade da perspectiva futura, a ilusão e a realidade no mesmo mito de consumo, a individualidade e a sociedade de massa. O culto das Stars foi outro tema pop. Belas faces encobrindo vulnerabilidades - o suicídio de Marilyn Monroe, a solidão de Elvis Presley, a depressão de Liz Taylor -, imagens despidas de valor e vulgarizadas pela maquiagem, ao mesmo tempo em que procuram representar a máscara do prazer consumista, os desejos e expectativas comercializados.

\footnotetext{
${ }^{16}$ OSTERWOLD, Tilman. Op. cit. P.136.

${ }^{17} \mathrm{O}$ "media" é a verdadeira mensagem, ele apenas comunica a si mesmo.

${ }^{18}$ HOBSBAWM, Eric. Op.cit. P.501.

${ }^{19}$ BENJ AMIN, Walter. Na era da reprodutibilidade técnica. P.14.

${ }^{20}$ ARGAN, Giulio Carlo. Arte Moderna. São Paulo. Cia das Letras, 1993. P.647.
}

$$
\text { Remile Yromiculs. }
$$


A iconografia da pop art abrange chupetas, gelados, seven-up, CocaCola, pasta dental, latas de conserva, cigarros, caixas de fósforo, hamburgueres, banheiras, pistolas, bandeiras americanas, o dólar. As banheiras são representadas por Wesselman em sua obra Grande Nu Americano $n^{\circ} 54 \mathrm{e}$ Banheira 3, lembrando o último trabalho de Duchamp, onde a noiva aparece totalmente despida. A Coca-Cola é o símbolo mor do capitalismo, sendo estilizada por Warhol desde 1960, assim como por Rauschenberg, Volf Vostell, e também por artistas contemporâneos como Cildo Meireles. Este, em sua obra Inserções em circuitos ideológicos: projeto coca-cola, opera uma provocação da ordem pública, como alguém que anonimamente mostra ao outro como é possível interferir nas estruturas que simbolizam o poder, desestatizando-as.

A representação das latas de conserva parecem concretizar as palavras de Duchamp: "As únicas obras de arte que a América produziu são utensílios sanitários e potes", fazendo referência ao seu trabalho. Warhol mostra a embalagem, mas não o conteúdo; mostra algo do conteúdo através da embalagem $^{21}$. Um objeto visual do estilo de vida quotidiano torna-se subitamente significativo e único, representando os hábitos e nivelamento das massas, como sinal de um tempo.

A enormidade, o gigantismo das obras pop tiram o aspecto trivial do objeto representado, mesmo aquele considerado o símbolo do país em crescimento, o "ícone" do sonho americano - a bandeira americana. Quando Jasper Johns a representa, levanta juntamente a questão: será uma bandeira ou uma pintura? "O representante da sociedade de massas começará por reconhecer a bandeira,... o representante da cena artística vai, por seu lado, reconhecer imediatamente um quadro" ${ }^{22}$, e no final, é tudo ao mesmo tempo.

A banalização da realidade americana vai ainda mais longe e despe de dignidade o dólar. "Enquanto moeda, o dólar é um valor abstrato que garante a segurança, enquanto nota, não é mais do que uma aparência, como um ícone tem o símbolo deposto da América" ${ }^{, 23}$. Warhol ilustra dólares inacabados para representar a fragilidade do símbolo da força americana, e faz um jogo psicológico com as personalidades que eles representam, banalizando-os. $\mathrm{Na}$ verdade, as obras de Warhol fazem-nos adquirir consciência de objetos que perderam seu reconhecimento visual através da exposição constante ${ }^{24}$.

Assim como o urinol de Duchamp foi rejeitado no Salão, as obras de Warhol também foram retiradas da exposição de 1965 no Institute of Contemporary Art de Filadélfia por medida de precaução. Elas nem chegaram a provocar o primeiro choque tão almejado por Duchamp, e característico da

\footnotetext{
${ }^{21}$ OSTERWOLD, Tilman. Op. cit. P.19.

${ }^{22}$ OSTERWOLD, Tilman. Op. cit. P.38.

${ }^{23}$ OSTERWOLD, Tilman. Op. cit. P.34.

${ }^{24}$ LUCIE-SMITH, Edward. Op. cit. P. 162. 
anti-arte. Mas Warhol, com ar de deboche, declarou: "É incrível, a inauguração de uma exposição sem arte",25.

O objetivo de Warhol era transformar o cotidiano e o insignificante em arte, inspirando-se na arte popular, na literatura banal e nos meios de comunicação. Seus primeiros quadros de temas publicitários passam, posteriormente, para clichês da vida hollywoodesca, numa relação entre destino pessoal e destino social, e adiante, para temas a respeito da violência e da morte (Catástrofe do Atum), como imagens catastróficas da sociedade mediática.

As técnicas da pop art são semelhantes as utilizadas pelos dadaístas, quais sejam, colagens, já usadas por Kurt Schwitters em 1947, assemblages, happening, como uma arte descartável, fotomontagens e colagens, utilizadas pelo artista pop Richard Hamilton. Warhol representa sua arte também através de blotted line (semelhante a frottage), e serigrafias sobre tela. Enquanto Warhol utilizava várias técnicas para expressar suas idéias, Duchamp negava as técnicas como produções programadas através dos ready-mades, atribuindo valor ao que não tem.

\section{Considerações Finais}

Warhol desnaturou a função pessoal: pela repetição calou a fisionomia e petrificou-a na impotência: um instante monumental, pois para ele, tudo é repetição numa época de comunicação e produção de massa. Nesse sentido... o que é a beleza? Para Warhol a beleza em si não é nada, o que vale é o critério de "quantidade como qualidade" 26 . E isso o artista demonstrou em várias obras em que repetiu a imagem de astros, do dólar, da Coca-cola, de latas de conserva, a fim de criticar e "dar uma nova aura" ao que já estava desgastado.

Contudo, Duchamp considera a técnica da reprodução uma falta de originalidade. Quando escolheu seus ready-mades, baseou-se numa reação de indiferença visual, independente de bom ou mau gosto, um estado de anestesia total, pois compreendeu que, para o espectador, mais que para o artista, a arte constituía um meio de conduzir ao vício. Portanto, foi contra tal processo de conspurcação que Duchamp lutou ${ }^{27}$. Não é a contemplação repetida das obras de arte que a leva à indiferença, pelo contrário, até a valoriza, mas é a repetição do tema que despoja o seu sentido, e lhe dá uma aparência vazia. O próprio Duchamp utilizou-se da repetição da mesma figura, estilizada diferentemente, a fim de "desteorizar" o cubismo, e chegar ao domínio do movimento.

Tanto Duchamp, como Warhol, destruíram estereótipos e construíram, além de uma nova imagem, uma nova filosofia para a arte. "Quando Duchamp

\footnotetext{
${ }^{25}$ OSTERWOLD, Tilman. Op. cit. P. 167.

${ }^{26}$ OSTERWOLD, Tilman. Op. cit, p. 177.

${ }^{27}$ RICHTER, Hans. Op. cit. P.117.
} 
põe bigodes na Gioconda de Leonardo, ele não pretende desfigurar uma obraprima, e sim, contestar a veneração que lhe tributa passivamente a opinião comum. E também, provavelmente, ferir o orgulho de um público que, agora, já não sabe distinguir entre original e reprodução, visto que a reprodução não possui carisma, é um fato industrial, podendo ser impunemente manipulada"28. Sua intenção é destituir de valor o que assim é considerado. Por outro lado, Duchamp faz uma alteração de juízo, ao atribuí-lo a um objeto da vida cotidiana a partir de um ato mental, e não de procedimentos técnicos. Warhol apropria-se desse mesmo objeto do cotidiano e da mídia, repetindo-o e interferindo neste, a fim de destruir um mito, e ironizar com uma "sociedade mascarada".

O traço típico dos americanos é o pragmatismo, sentido das realidades, objetividade, otimismo, faceta de entertainment; gosto pelos bens de consumo, pela trivialidade, pela publicidade e cinema, pela banalidade e vulgaridade. Todos esses traços estão voltados à satisfação dos desejos e a busca do prazer, o que não retrata uma anti-arte, mas objetos destinados ao prazer. Nesse sentido, a pop art não se origina do nada, como era intenção dos dadaístas, mas de uma intenção bem planejada. Todavia, o sentido da arte, em ambos movimentos, é de destruição, e o happening é um exemplo da tendência para a arte descartável. "Se a arte pop foi a primeira a ser propositadamente feita para não durar, a implicação é clara $^{29}$. A paixão pela obsolência não era uma excentricidade - equivalia a uma declaração de que daí em diante nenhuma arte seria durável. Tudo na arte pop era - e é - transitório e provisório. Ao adotarem essas qualidades, os artistas pop ergueram um espelho onde a própria sociedade se vê refletida" 30 .

Por alguma razão, os artistas da pop art escolheram Duchamp como santo padroeiro, e o colocaram num nicho de honra. Mas Duchamp escapou rapidamente deste nicho ${ }^{31}$. Esse artista da anti-arte eternizou não somente sua obra, mas também sua teoria da arte, a qual é fonte de inspiração para os contemporâneos, e a foi para os artistas pop. Todavia, mesmo lutando contra os preceitos tradicionais da museologia, acabou ganhando uma sala no Museu da Filadélfia. Será que Duchamp foi incompreendido, ou fracassou?

Creio que Duchamp não escapou do nicho, mas foi interpretado dentro do contexto de outras épocas. Dessa forma, quando Warhol expõe Thirteen Most Wanted Men - a partir de panfletos do FBI que apresentam criminosos

\footnotetext{
${ }^{28}$ ARGAN, Giulio Carlo. Op. cit. P.356.

${ }^{29}$ Creio que neste trecho o autor comete um engano ao afirmar que a pop art foi a primeira a realizar uma arte não duradoura. Esquece-se o autor de que o dadá, ao ter apostado no acaso e na espontaneidade absoluta, "confiou" apenas no momento, e destruiu as obras que ultrapassaram esse período.

${ }^{30}$ LUCIE-SMITH, Edward. Op. cit. P.169.

${ }^{31}$ RICHTER, Hans. Op. cit. P, 290.
} 
procurados, em 1964 na fachada do Pavilhão do Estado de Nova Iorque -, ele prova que entendeu Duchamp, porque provocou o primeiro choque e soube criticar a sociedade e a museologia, apresentando seu trabalho fora de um museu.

Como afirma Jorge Coli, "o importante é termos em mente que o estatuto da arte não parte de uma definição abstrata, lógica ou teórica, do conceito, mas de atribuições feitas por instrumentos de nossa cultura, dignificando os objetos sobre os quais ela recai" ${ }^{, 32}$. Tanto Duchamp, como Warhol fizeram parte de uma mesma cultura americana, e dignificaram seus objetos a partir do momento em que expressaram nesses, mais do que conceitos, a historicidade de sua época.

${ }^{32}$ COLI, Jorge. O que é arte. São Paulo, Ed. Brasiliense, 2000. P.11. 